\title{
Ten years of Educational Robotics in a Primary School
}

\author{
Mariantonietta Valzano, Cinzia Vergine, Lorenzo Cesaretti, \\ Laura Screpanti, and David Scaradozzi
}

\begin{abstract}
Many researchers and teachers agree that the inclusion of science, technology, engineering, and mathematics in early education provides strong motivation and greatly improves the speed of learning. Most primary school curricula include a number of concepts that cover science and mathematics, but less effort is placed in teaching problem-solving, computer science, technology and robotics. The use of robotic systems and the introduction of robotics as a curriculum subject educates children in the basics of technology, and gives them additional human and organizational values. This paper presents a new program introduced in an Italian primary school, thanks to a collaboration with National Instruments and Università Politecnica delle Marche. Specifically, the project's curricular aim was to improve logic, creativity, and the ability to focus, all of which are lacking in today's generation of students. The subject of robotics will be part of the primary school's curriculum for all five years. The program has delivered training to the teachers, and a complete program in which children have demonstrated great learning abilities, not only in technology, but also in collaboration and teamwork.
\end{abstract}

Keywords Educational robotics $\cdot$ Primary school $\cdot$ Curricular robotics

\footnotetext{
M. Valzano $(\varangle) \cdot$ C. Vergine

ICS Largo Cocconi, Largo G. Cocconi, 10 - 00171, Roma, Italy

L. Cesaretti $\cdot$ L. Screpanti $\cdot$ D. Scaradozzi

Dipartimento Di Ingegneria Dell'Informazione (DII), Università Politecnica Delle Marche, Via Brecce Bianche, 60131 Ancona, Italy

e-mail: d.scaradozzi@univpm.it

D. Scaradozzi

LSIS - Umr CNRS 6168, Laboratoire Des Sciences de L'Information et des Systèmes, Equipe I\&M (ESIL), case 925 - 163, avenue de Luminy, 13288 Marseille cedex 9, France
}

D. Scaradozzi et al. (eds.), Makers at School, Educational Robotics and Innovative

Learning Environments, Lecture Notes in Networks and Systems 240,

https://doi.org/10.1007/978-3-030-77040-2_38 


\section{Introduction}

Many researchers have been investigating the use of robots to support education [1-4]. Studies have shown that robots can help students develop problem-solving abilities and learn computer programming, mathematics, and science [5-8] and [9]. The educational approach is based mainly on fostering logic and creativity in today's generation of students, who are at the beginning of their educational journey. Learning to program robots is an opportunity for primary school students to develop their linguistic and logical skills [10, 11 to focus on pedagogical rather than technological issues. This paper presents an innovative program that was developed to teach the basics of robotics as a curricular subject in primary schools. The same methods are used in other subjects (Italian, mathematics, science, etc.) to provide multidisciplinary validation and motivation. Education in Italy is compulsory from the ages of 6-16, and is divided into five stages: kindergarten (scuola dell'infanzia), primary school (scuola primaria), lower secondary school (scuola secondaria di primo grado or scuola media), upper secondary school (scuola secondaria di secondo grado or scuola superiore) and university. The main subjects are Italian, English, mathematics, natural sciences, history, geography, social studies, physical education and visual and musical arts. The five-year program for primary schools is divided into two main blocks. During the first two years, students are introduced to robotics, including learning what a robot is, what kinds of rules it follows, how to build a puppet, then a machine using everyday materials, and finally using the Lego WeDo system [12]. In the last three years, children have been building and programming robots with the Lego NXT system. LEGO Education WeDo is an easy-to-use robotics platform that introduces young students to hands-on learning through LEGO bricks. It is the easiest graphical programming software that National Instruments has to offer. It is a fun and simple way to expose young students to basic engineering concepts at an early age. LEGO Education WeDo provides a hands-on learning experience that actively engages children's creative thinking, teamwork, and problem-solving skills. It is a hands-on platform that primary school students can use to build simple robotics applications which are controlled in a simplified version of LabVIEW installed on a personal computer. By combining the intuitive and interactive interface of LEGO Education WeDo software with the physical experience of building models out of LEGO bricks, students can bridge the physical and virtual worlds for the ultimate hands-on, minds-on learning experience (LabVIEW Graphical System Design) [13]. The system has been applied in primary schools in other countries, and the potential benefits for children's education have been studied. Mayerovà's study [14], for example, analyzes the first encounter of third-grade primary school students with LEGO WeDo. Romero [15] describes a pilot study of robotics in primary schools, together with the reasons for choosing LEGO WeDo for the children's activities, namely, the programming language's shallow learning curve (visual programming rather than code writing), and the educational content provided. In recent years, National Instruments, Università Politecnica delle Marche and primary schools have 
collaborated on improving the use of new technologies from the first grade of school. One of the schools involved is Istituto Comprensivo Largo Cocconi.

Following previous pedagogical, technological and educational experiences in numerous institutions, this project arose from a collaboration between researchers at Università Politecnica delle Marche (UNIVPM) and teachers at Istituto Comprensivo Largo Cocconi. This paper will present the different aspects of the project and the preliminary results. The presentation is organized as follows: Sect. 2 describes the objectives and the expected results of the project; Sect. 3 explains the tools used and the timeline of the project; Sect. 4 illustrates the preliminary results; the conclusions and future developments are illustrated in Sect. 5.

\section{Objectives and Expected Results}

The first and main aim of this project concerns the introduction of robotics into primary schools as a standard curricular subject, rather than as an extracurricular activity outside of school hours. The specific goals of the project include increasing children's abilities, teaching them to program a machine, and getting them to consider robotics a normal method of working, rather than an exceptional activity. Robotics gives students another opportunity to develop their logical skills and their creativity [16], both key to reasoning and critical thought. The first stage of the experiment, which took place between 2010 and 2015, covered an entire five-year period of primary school. The priority set was to introduce ROBOTICS as a curriculum subject, improving the usual competences reported in the regular national plans for education with a new teaching theme. Now the classes of the ROBOTIC Institute run throughout the school year, and teachers hold regular meetings to compare notes on their skills and results. Each class can schedule and organize teaching units that are specific to their students, by matching them to the topics of ordinary lessons. The new study program is presented below for the five years that make up primary school. The main objectives of the project are as follows:

1. Grade I

- Getting to know the concepts of robotics with the introduction of Asimov's literature and the three laws of robotics;

- Learning about individual mechanical elements through simplified ordering and planning programs: learning the differences between the shapes, materials, colors and functionalities of the elements available on the market;

- Planning a model in the LEGO system using a simplified program;

- Understanding the concepts of verification and validation of the model in the work environment.

- Introduction of Lego NXT-EV3 and different devices.

2. Grades II-III

- Acquiring the ability to attribute coherent purpose to a constructed robot; 
- Introduction to the concept of the ROBOT as a machine that has to complete a specific task;

- Studying sensors and actuators by comparing them with systems in the human body;

- Introduction to the programming environment for the LEGO WeDo system.

- Building a simple robot that can interact with its surroundings.

3. Grades IV-V

- Acquiring the ability to attribute coherent purpose to a complex constructed robot;

- Acquiring the ability to build a robot with specific and relatively complex objectives.

- Planning a robot for a specific research purpose, which can live in a defined environment.

- Introduction to software for robot analysis.

- Creating a technical manual for the final operator explaining how to design and build a robot.

In the last two school years, the project introduced students to distributed control in the robotic environment using the SAM LABS educational kit [17]. The new activity begins in fourth grade classes by teaching students the differences between central control and distributed control in the environment. They analyze real situations like smart traffic lights, heating and air-conditioning systems, etc. [18]. In the fifth grade, students can use the same material to design their own distributed control inventions. These robotics units are designed with an interdisciplinary approach. They are linked to other subjects — physical education, history, geography and languagewhich helps to introduce an integrated and combined path to knowledge construction. The method is applied to the same scientific procedures: observing, thinking, verifying. The children's work teams are organized by roles and skills, and change during the year, improving inclusive behaviors and cooperative learning.

\section{Instruments and Time}

These activities take place during the hours set aside in the weekly timetable "for optional subjects", as required by the Ministry of Education. The program includes educational trips related to the topics the students are learning. These trips begin in the second and third grades of primary school, and may be to science museums or research institutes, where students get involved in more specific workshops about mechatronics and robotics. The hardware and software for this project include five kits of LEGO WeDo for the first and second grades and five Kits of LEGO MINDSTORMS NXT in the other grades. 
Table 1 INVALSI [19] tests of 2015 experimental fifth class

\begin{tabular}{l|l|l|l|l|l}
\hline $\begin{array}{l}\text { Average } \\
\text { percent score } \\
\text { (net of } \\
\text { cheating, 2019) }\end{array}$ & $\begin{array}{l}\text { Students' score } \\
\text { (net of } \\
\text { cheating, 2019) } \\
\text { in the same } \\
\text { scale of the } \\
\text { national report }\end{array}$ & $\begin{array}{l}\text { Percent score } \\
\text { difference } \\
\text { comparing } \\
\text { classes/schools } \\
\text { with similar } \\
\text { familiar } \\
\text { background }\end{array}$ & $\begin{array}{l}\text { Average } \\
\text { familiar } \\
\text { background }\end{array}$ & $\begin{array}{l}\text { Percent } \\
\text { observed } \\
\text { score }\end{array}$ & $\begin{array}{l}\text { Percent } \\
\text { cheating }\end{array}$ \\
\hline 64.1 & 212.4 & 6.0 & Low & 66.5 & 4.0 \\
\hline
\end{tabular}

\section{Results}

The results are based on the activities described in Sect. 2. The proposed criteria taught new concepts to children, enabled them to attribute coherent purpose to a constructed robot, and taught them robotics, including an introduction to Asimov's three laws of robotics. Selected groups of professional operators will also be invited to observe and to take part in the intermediate tests and experiments. Observations from the first experiment of robotics taught as a curricular subject led by primary school teacher Mariantonietta Valzano and Professor David Scaradozzi at the Istituto Comprensivo Largo Cocconi in Rome are that logic, attention and focus improved significantly in these primary school students, as did their team work skills. After evaluating these results and comparing them with different students in classes of the same level, it was seen that the children who completed the entire robotics program attained higher levels of competence, and acquired the skills that were planned for them faster and more profoundly. This in turn changed behaviors within the class and improved social inclusion.

The first result was clear when comparing INVALSI [19] 2015 tests with those of the fifth-grade participants in the experiment (see Table 1).

Average Score Lazio: 56.3

Average Score Central Italy: 57.4

Average Score Italy: 56.6.

According to these results, students who completed an educational robotics course attained a higher degree of competence compared with students in classes from the same school and the countrywide average.

\section{Conclusion}

The teachers in the project have recorded significant improvements in their students, which demonstrates the important value of using robotic systems in all aspects of teaching. Students have been very curious and passionate during these activities, 
exploring tasks like robot design and programming, and developing important life skills like teamwork and problem-solving.

This curriculum project has focused on increasing and pursuing creativity and logical thinking as important educational skills in modern school. The good results obtained since the start of the project in 2010 have convinced the school's teachers and head teacher to involve other classes in the experiment. Now nine classes have introduced robotics as a regular subject.

Finally, SAM LABS and IoT have also been introduced, allowing students to learn what these innovative technologies are bringing to our lives.

\section{References}

1. Scaradozzi, D., Cesaretti, L., Screpanti, L., Costa, D., Zingaretti, S., Valzano, M.: Innovative tools for teaching marine robotics, IoT and control strategies since the primary school. In: Smart Learning with Educational Robotics, pp. 199-227. Springer, Cham (2019)

2. Scaradozzi, D., Screpanti, L., Cesaretti, L.: Towards a definition of educational robotics: a classification of tools, experiences and assessments. In: Smart Learning with Educational Robotics, pp. 63-92. Springer, Cham (2019)

3. Screpanti, L., Cesaretti, L., Marchetti, L., Baione, A., Natalucci, I.N., Scaradozzi, D.: An educational robotics activity to promote gender equality in STEM education. In: International Conference on Information, Communication Technologies in Education (ICICTE 2018) Proceedings. Chania, Greece (2018)

4. Scaradozzi, D., Screpanti, L., Cesaretti, L., Mazzieri, E., Storti, M., Brandoni, M., Longhi, A.: Rethink Loreto: we build our smart city!" A stem education experience for introducing smart city concept with the educational robotics. In: 9th Annual International Conference of Education, Research and Innovation (ICERI 2016). Seville, Spain (2016)

5. Atmatzidou, S., Demetriadis, S.: Advancing students' computational thinking skills through educational robotics: a study on age and gender relevant differences. Robot. Auton. Syst. 75, 661-670 (2016)

6. Cesaretti, L., Storti, M., Mazzieri, E., Screpanti, L., Paesani, A., Scaradozzi, D.: An innovative approach to school-work turnover programme with educational robotics. Mondo Digitale 16(72), 2017-2025 (2017)

7. Kandlhofer, M., Steinbauer, G.: Evaluating the impact of educational robotics on pupils' technical-and social-skills and science related attitudes. Robot. Auton. Syst. 75, 679-685 (2016)

8. Sullivan, F.R.: Robotics and science literacy: thinking skills, science process skills and systems understanding. J. Res. Sci. Teach. Official J. National Assoc. Res. Sci. Teach. 45(3), 373-394 (2008)

9. Scaradozzi, D., Screpanti, L., Cesaretti, L., Storti, M., Mazzieri, E.: Implementation and assessment methodologies of teachers' training courses for STEM activities. Technol. Knowl. Learn. 24(2), 247-268 (2019)

10. Scaradozzi, D., Pachla, P., Screpanti, L., Costa, D., Berzano, M., Valzano, M.: Innovative robotic tools for teaching STREM at the early stage of education. In: Proceedings of the 10th annual International Technology, Education and Development Conference, INTED (2016)

11. Scaradozzi, D., Sorbi, L., Pedale, A., Valzano, M., Vergine, C.: Teaching robotics at the primary school: an innovative approach. Procedia Soc. Behav. Sci. 174, 3838-3846 (2015)

12. Lego Wedo Education (2019), https://education.lego.com/en-gb/product/wedo

13. LabVIEW Graphical System Design—From Kindergarten to Rocket Science, http://www.ni. com/newsletter/50596/en/

14. Mayerová, K.: Pilot activities: LEGO WeDo at primary school. In: Proceedings of 3rd International Workshop Teaching Robotics, Teaching with Robotics, pp. 32-39 (2012) 
15. Romero, E., Lopez, A., Hernandez, O.: A pilot study of robotics in elementary education. In: 10th Latin American and Caribbean Conference for Engineering and Technology. Panama City, Panama (2012)

16. Eguchi, A.: Educational robotics for promoting 21st century skills. J. Autom. Mobile Robot. Intell. Syst. 8(1), 5-11 (2014)

17. SAM LABS (2019) https://samlabs.com/

18. Morganti, G., Perdon, A. M., Conte, G., Scaradozzi, D.: Multi-agent system theory for modelling a home automation system. In: International Work-Conference on Artificial Neural Networks, pp. 585-593. Springer, Berlin, Heidelberg (2009)

19. Net of Cheating (2019), http://www.invalsi.it/invalsi/ri/sis/documenti/022013/falzetti.pdf

Open Access This chapter is licensed under the terms of the Creative Commons Attribution 4.0 International License (http://creativecommons.org/licenses/by/4.0/), which permits use, sharing, adaptation, distribution and reproduction in any medium or format, as long as you give appropriate credit to the original author(s) and the source, provide a link to the Creative Commons license and indicate if changes were made.

The images or other third party material in this chapter are included in the chapter's Creative Commons license, unless indicated otherwise in a credit line to the material. If material is not included in the chapter's Creative Commons license and your intended use is not permitted by statutory regulation or exceeds the permitted use, you will need to obtain permission directly from the copyright holder. 